\title{
Foreword Celebrating the career of Professor Kuniaki Tatsuta
}

The Journal of Antibiotics (2013) 66, 103; doi:10.1038/ja.2013.5

A s Editor-in-Chief, I am extremely pleased that a special edition of The Journal of Antibiotics will be issued in honor of Professor Kuniaki Tatsuta in recognition of his brilliant research achievements and accomplishments in the field of teaching, as well as his invaluable contributions to the development of the Journal.

I am also very happy that this special edition received numerous submissions from researchers active in the natural products organic chemistry field, which will make the edition truly meaningful.

Honorary Fellow and Emeritus Professor of Waseda University, Dr Kuniaki Tatsuta was born in 1940 in Osaka, Japan, and received his $\mathrm{PhD}$ from Keio University in 1969 under the direction of Professor S Umezawa. He later carried out postdoctoral studies with Professor RB Woodward at Harvard University (1973-1975). In 1985, he became a Professor in the Faculty of Science and Technology, Keio University before moving to Waseda University in 1993 as Professor of Bioactive Substances Science, being appointed as Dean of the Graduate School of Science and Engineering there in 2004. He held Visiting Professorships at Cambridge (1988), Paris VI (1994) and Oxford Universities (2006) and has been a long-serving member of the Editorial Board of The Journal of Antibiotics.

Sir Derek Barton calls Professor Tatsuta 'Dr Total Synthesis', a straightforward indicator of his breakthrough results in the synthesis of natural products. Professor Tatsuta is particularly well known for achieving the total synthesis of four classes of major natural products-Tetracyclines, Aminoglycosides, Macrolides and $\beta$-Lactam antibiotics. He has achieved more than 100 total syntheses, and of these, he was the first in the world to synthesize 95 compounds, indicating his eagerness to take on difficult challenges and his creativity, as well as his exceptional skill. The natural products that Professor Tatsuta targeted for total synthesis have numerous functional groups, and achieving total synthesis required adoption of novel strategies and development of many new techniques. Typically,
Tatsuta's work demonstrates new methods for transforming carbohydrates, including innovative methods for the synthesis of deoxyglycosides that have significantly increased the value of carbohydrates as starting materials.

He has also synthesized several useful derivatives of natural products. Through total syntheses of glycosidase inhibitors, he demonstrated for the first time the theoretical possibilities of chemically creating inhibitors against all glycosidases and developed useful anti-diabetes agents. In addition, a new anticancer agent, THPadriamycin (commercialized as pirarubicin in 1988), was synthesized by him through his synthetic studies on anthracyclines. He also succeeded in synthesizing cefozopran, which was marketed in 1995. I would like to make special note of his particular contributions to the development of The Journal of Antibiotics, including the 75 papers that he has published in this Journal.

Tatsuta's extraordinary contributions to natural products chemistry have been repeatedly recognized, as indicated by his several awards and honors, including the Sumiki-Umezawa Memorial Award (1988), the Distinguished Award of the Chemical Society of Japan (2001), the National Medal with Purple Ribbon of Japan (2002), the Fujihara Award (2008), the Japan Academy Prize (2009) and the Special Award in Synthetic Organic Chemistry Japan (awarded in February, 2013), as well as his honorary membership of the Chemical Society of Japan. This year, the American Chemical Society will also honor him with its prestigious Ernest Guenther Award.

Satoshi Ōmura Editor-in-Chief Kitasato Institute for Life Sciences, Kitasato University, Minato-ku, Tokyo, Japan E-mail: omuras@insti.kitasato-u.ac.jp 